Research report

\title{
Inhibiting 12/15-lipoxygenase to treat acute stroke in permanent and tPA induced thrombolysis models
}

\author{
H. Karatas ${ }^{\mathrm{a}, \mathrm{b}, *}$, Joo Eun Jung ${ }^{\mathrm{a}}$, E.H. Lo ${ }^{\mathrm{a}}$, K. van Leyen ${ }^{\mathrm{a}}$ \\ a Massachusetts General Hospital, Harvard Medical School, Neuroprotecgtion Research Laboratory, Department of Radiology, Charlestown, MA, USA \\ ${ }^{\mathrm{b}}$ Hacettepe University, Institute of Neurological Sciences and Psychiatry, Ankara, Turkey
}

\section{A R T I C L E I N F O}

\section{Article history:}

Received 31 August 2017

Received in revised form 20 October 2017

Accepted 23 October 2017

Available online 24 October 2017

\section{Keywords:}

12/15-LOX

$\mathrm{FeCl}_{3}$

tPA

Stroke models

Reperfusion

\begin{abstract}
A B S T R A C T
12/15-Lipoxygenase (12/15-LOX) contributes to the brain damage after middle cerebral artery occlusion (MCAO) in the acute phase of stroke. The aim of this study was to investigate the effects of a 12/15-LOX inhibitor, LOXBlock-1(LB1), in mice using a $\mathrm{FeCl}_{3}$-induced permanent distal $\mathrm{MCAO}$ model and $\mathrm{FeCl}_{3}$ induced ischemia/thrombolysis with tPA. In order to induce permanent distal $\mathrm{MCAO}, 30 \% \mathrm{FeCl}_{3}$ was used in C57BL6 mice. LB1 or DMSO treatments were applied intraperitoneally $2 \mathrm{~h}$ following MCAO. For $\mathrm{FeCl}_{3-}$ induced ischemia/thrombolysis experiments, $10 \% \mathrm{FeCl}_{3}$ was preferred so as to obtain reperfusion with tPA in CD1 mice. $4 \mathrm{~h}$ following ischemia either LB1 or DMSO and iv tPA was administered. Outcomes were $\mathrm{NSS}$, weight loss, infarct volume, hemorrhage area and reperfusion rate. $\mathrm{FeCl}_{3}$-induced distal $\mathrm{MCAO}$ caused an increase in 12/15-LOX signal in the ischemic cortex with an increase in MDA2 and AIF immunoreactivity. LB1 treatment, applied $2 \mathrm{~h}$ after ischemia, significantly decreased the infarct volume at $24 \mathrm{~h}$ of permanent distal MCAO. Weight loss was also significantly reduced in LB1 treated group. Distal MCAO and tPA application with LB1 or DMSO showed that treatment significantly decreased the infarct volume and the hemorrhage area. The reperfusion rate in the LB1-treated group was surprisingly higher than in the DMSO group and NSS results were significantly improved. These data suggest that LB1 can be used as an adjuvant agent to tPA. This study not only shows the effects of LB1 treatment in distal MCAO but also confirms that $\mathrm{FeCl}_{3}$-induced MCAO model can be a useful tool to screen novel treatment options in stroke.
\end{abstract}

(c) 2017 Elsevier B.V. All rights reserved.

\section{Introduction}

Stroke is the leading cause of disability and the fifth leading cause of death in the United States (Writing Group et al., 2016). On average, every 4 min a human dies of stroke (Lackland et al., 2014; Writing Group et al., 2016). Together with cardiovascular diseases, its economic burden is higher than the other diagnostic groups including cancer. The annual direct and indirect cost of cardiovascular diseases and stroke is an estimated $\$ 316.6$ billion in the United States (Writing Group et al., 2016). Despite these catastrophic effects of stroke, the only FDA-approved drug treatment option for acute stroke is the application of tissue plasminogen activator (tPA) which has many drawbacks including the narrow time window, low rate of reachable patients, and severe side effects including hemorrhage (Kaur et al., 2004; Lees et al., 2010; National Institute of Neurological Disorders and stroke rt-PA

\footnotetext{
* Corresponding author at: Hacettepe University, Institute of Neurological Sciences and Psychiatry, Sihhiye, Ankara 06100, Turkey.

E-mail address: hulyak@hacettepe.edu.tr (H. Karatas).
}

Stroke Study Group, 1995; Wang et al., 2004; Yepes et al., 2009). New treatment options are thus of great interest in stroke management, and screening for novel drugs in animal models is an important drug development approach. Besides STAIR advices to use different animal stroke models both permanent and transient and also with reperfusion and with thrombolysis (Fisher et al., 2009). The great majority of ischemic strokes are due to an occlusion in a cerebral artery by a thrombus especially in the middle cerebral artery (MCA) in human (Hossmann, 2012). So it is feasible to choose a model that mimics human stroke like $\mathrm{FeCl}_{3}$-induced MCA occlusion model to test novel drugs (Denorme et al., 2016). Stroke damages the neurovascular unit, causes massive cell death and activates several oxidative stress-related pathways like lipid peroxidation, during its acute phase (Hardingham and Lipton, 2011; Lo et al., 2003; Lo et al., 2005; Moskowitz et al., 2010; Niizuma et al., 2009). Lipoxygenases play one of the major roles in stroke related oxidative stress. Especially 12/15-lipoxygenase, the dominant isoform in the brain, is increased in neurons and endothelial cells in the peri-infarct area, contributing to delayed cell death in the penumbra, weakening of the blood-brain barrier, 
and resulting in edema formation (Jin et al., 2008; van Leyen et al., 1998; van Leyen et al., 2006; van Leyen et al., 2014). Therefore, lipoxygenase inhibitors are in scope of acute stroke treatment research, and among them LOX Block-1 (LB-1) is a new candidate considering its potential (Yigitkanli et al., 2013).

The current study was designed to investigate the effects of the 12/15-LOX inhibitor, LOXBlock-1 (LB1) in mice using a $\mathrm{FeCl}_{3}$ induced distal MCAO model, and to test its utility in conjunction with subsequent thrombolysis with tPA, which is to date the only FDA-approved drug for acute stroke treatment. This study will help us to improve our knowledge about the effect of LB-1 in different models of stroke other than previously used reperfusion models.

\section{Results}

\subsection{Permanent distal MCAO results}

Our previous findings documented increased levels of 12/15LOX in transient models of focal (Jin et al., 2008; van Leyen et al., 2006; Yigitkanli et al., 2013) and global ischemia (Yigitkanli et al., 2017), where reperfusion and its associated injury is part of the pathology. We here used a mouse model of distal MCAO induced by topical application of $30 \% \mathrm{FeCl}_{3}$ to determine if $12 / 15$-LOX is also upregulated in permanent focal ischemia, in the absence of reperfusion. $30 \% \mathrm{FeCl}_{3}$ reliably and stably occludes the MCAO and consistently leads to highly reproducible infarcts, as previously shown by Karatas et al. (2011). 30\% $\mathrm{FeCl}_{3}$-induced distal MCAO caused increased LOX immunoreactivity in the ischemic cortex, particularly in the peri-infarct area of the cortex, compared to contralateral intact cortex and sham operated brains. This was accompanied by increases in an oxidative stress marker MDA2, and a marker for apoptosis, AIF, both of which were similarly elevated ( $n=2 /$ groups) (Fig. $1 A-R)$. Interestingly MDA2 immunoreactivity was more widely distributed and also present in cells that were not LOX-positive.

After observing the contribution of 12/15 lipoxygenase in the $\mathrm{FeCl}_{3}$-induced distal MCAO model, we investigated the effect of the lipoxygenase inhibition in this model by systemically administering a lipoxygenase blocker, LB1. LB1 treatment, applied $2 \mathrm{~h}$ after ischemia, significantly decreased infarct volume at $24 \mathrm{~h}$ of permanent distal MCAO ( $\mathrm{p}<.05, \mathrm{n}=6$ /group) (Fig. 2A). Infarct volume of the vehicle group was $53.0 \pm 5.9 \mathrm{~mm}^{3}$, whereas in the LB1 treated group was $12.3 \pm 2.8 \mathrm{~mm}^{3}$. NSS results were lower in LB1 treated group compared to vehicle injected group ( $2.5 \pm 1.0$ versus $3.2 \pm$ 1.4 respectively) but the difference was not statistically significant (Fig. 2B). Weight loss after $24 \mathrm{~h}$ of ischemia was also significantly less in LB1 treated group ( $1.5 \pm 0.3 \mathrm{~g}$ versus $2.8 \pm 0.4 \mathrm{~g}$ ) (Fig. $2 \mathrm{C}$ ).

\subsection{Ischemia/tPA induced reperfusion groups results}

For ischemia/reperfusion studies in this model of distal MCAO, $10 \% \mathrm{FeCl}_{3}$ was chosen to induce thrombosis in MCA due to the fact that this concentration of $\mathrm{FeCl}_{3}$ causes a fresh thrombus to be formed that can be lysed by antithrombolytic agents like tPA (Karatas et al., 2011). Distal MCAO was performed using $10 \% \mathrm{FeCl}_{3}$ and $4 \mathrm{~h}$ after the onset of ischemia, $10 \mathrm{mg} / \mathrm{kg}$ tPA was applied added to either LB1 treatment $(n=8)$ or vehicle treatment $(n=$ 9 ). Results of the experiments showed that application of tPA plus LB1 treatment significantly decreased infarct volume and hemorrhage area, compared to the application of vehicle plus tPA treatment (Fig. 3A). Infarct volume of vehicle plus tPA treatment group was $48.0 \pm 4.4 \mathrm{~mm}^{3}$ whereas LB1 plus tPA treatment group's infarct volume was $23.7 \pm 2.5 \mathrm{~mm}^{3}(\mathrm{p}=.004)$. Hemorrhage area of vehicle group was $22.4 \pm 2.7 \mathrm{~mm}^{2}$ and in LB1 treated group it was $8.8 \pm 1.6 \mathrm{~mm}^{2}$ ( $\mathrm{p}=.001$ ) (Fig. $3 \mathrm{~B}$ ). It also noteworthy that success- ful reperfusion was achieved more frequently in the LB1 treated group (5/8) than in the vehicle group (2/9). There was no significant difference in ischemia and reperfusion levels between groups. In vehicle treated group rCBF drop was $29 \pm 3 \%$ and $\mathrm{rCBF}$ increase after reperfusion was $47 \pm 17 \%$ whereas in the LOXBlock- 1 treated group, rCBF drop was $24 \pm 3 \%$ and increase after reperfusion was $62 \pm 11 \%$.

NSS results were significantly lower in LB1 treatment $(3 \pm 1)$ compared to vehicle treatment $(5 \pm 1)(\mathrm{p}=.046)$ (Fig. 3C). Although the weight loss of the mice after $24 \mathrm{~h}$ of ischemia/reperfusion were improved in LB1-treated group ( $3.3 \pm 0.5 \mathrm{~g}$ versus $4.4 \pm 0.6 \mathrm{~g}$ ), the difference was not statistically significant (Fig. 3D).

\section{Discussion}

Within this study, as proven using the immunohistochemical methods, we have demonstrated that lipoxygenase activation has a vital contribution in the pathophysiology of ischemia in the $\mathrm{FeCl}_{3}$-induced distal MCAO model. Previously, Khanna et al. (Khanna et al., 2005; Park et al., 2011) and our group have reported the involvement of 12/15-LOX in proximal MCAO models (Jin et al., 2008; van Leyen et al., 2006; Yigitkanli et al., 2013). However, considering a distal MCAO model, this is the first report demonstrating an increased LOX immunoreactivity in the ischemic cortex and in the peri-infarct area. This immunoreactivity was colocalized with an oxidative stress marker, malondialdehyde (MDA2) (Fig. 1A-C). Malondialdehyde is a breakdown product formed by the oxidation of arachidonic acid. Increased LOX immunoreactivity was also coincidental with the AIF immunopositivity in the peri-infarct area (Fig. 1J-L). AIF is known to be increased following ischemia (Zhao et al., 2004), and the staining pattern closely resembles what we have found in our previously published data, where 12/15-LOX and AIF were both increased in the peri-infarct region (Pallast et al., 2010). This immunoreactivity was also found in human stroke patients in the peri-infarct area (Yigitkanli et al., 2013).

Consistent with a damaging role for increased 12/15-LOX activity in stroke, systemic administration of the 12/15-LOX inhibitor, LB1, $2 \mathrm{~h}$ after permanent focal cerebral ischemia significantly reduced infarct size $24 \mathrm{~h}$ after the ischemia, and the treatment group demonstrated improved behavioral and health parameters. Finally, we investigated the effects of a combination therapy of lipoxygenase inhibitor with tPA in $\mathrm{FeCl}_{3}$-induced transient ischemia-reperfusion model. LB1 treatment applied $4 \mathrm{~h}$ after ischemia onset which was followed by thrombolysis with tPA, significantly decreased infarct volume and hemorrhage area accompanying with better NSS results and reduced weight loss. It might demonstrate that 12/15-LOX inhibition provides benefits when coadministered with tPA after stroke. Yigitkanli et al. also supports our results with the data made $2 \mathrm{~h}$ after ischemia onset in filament-induced proximal MCAO model (Yigitkanli et al., 2013). It was previously shown that application of intraperitoneal LB1 treatment either 2, 4 or $6 \mathrm{~h}$ after filament-induced focal cerebral ischemia decreased infarct volume (Yigitkanli et al., 2013), and our results here suggest a similar time window for this distal model.

In this study it was shown that lipoxygenase activity contributes to the stroke pathophysiology and inhibition of this activity decreases infarct volume in acute distal MCA ischemia model. This study and previous studies also showed that lipoxygenase inhibitors are safe against hemorrhage after stroke when administered alone or even with tPA treatment (Liu et al., 2017; Yigitkanli et al., 2013). This safe time window is $4 \mathrm{~h}$ after stroke yet we did not investigate the effects beyond this time window. In addition, inhibition of 12/15-LOX activity strengthens the effect of tPA in accordance with decreased infarct volume and better NSS results. 


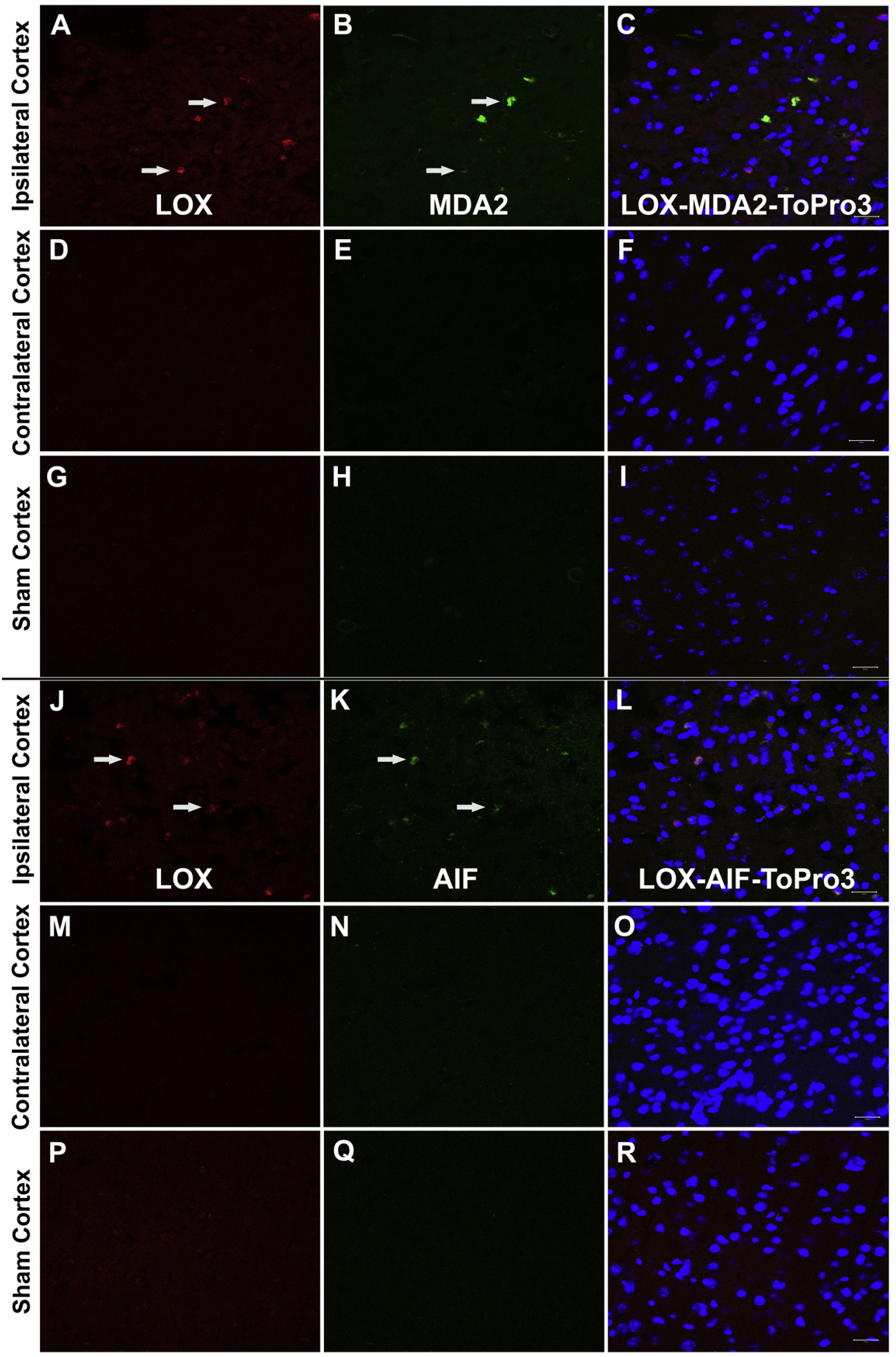

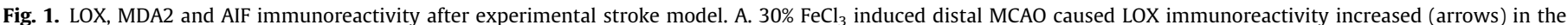

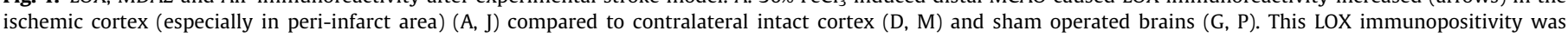

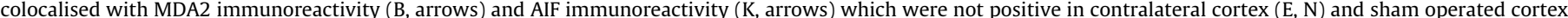
$(\mathrm{H}, \mathrm{Q})$. Merged images of LOX, MDA2 or AIF and ToPro3 are shown in C, F, I, L, O, R. Scale bars $=20 \mu \mathrm{m}$ ).

This effect might result from the decrease in the blood-brain barrier permeability through application of the 12/15 LOX inhibitor after stroke (Jin et al., 2008).

Recently it was shown that not only tPA-induced hemorrhage, but also warfarin-associated hemorrhagic transformation was significantly reduced using a novel lipoxygenase inhibitor with and without tPA administration (Liu et al., 2017). These results show that 12/15-LOX inhibitors may be a good option to prevent thrombolysis-induced side effects of acute stroke treatment. Also these inhibitors might be used in human acute stroke patients without tPA in the ambulance as it is safe against hemorrhage and effectively decreases infarct volume. 

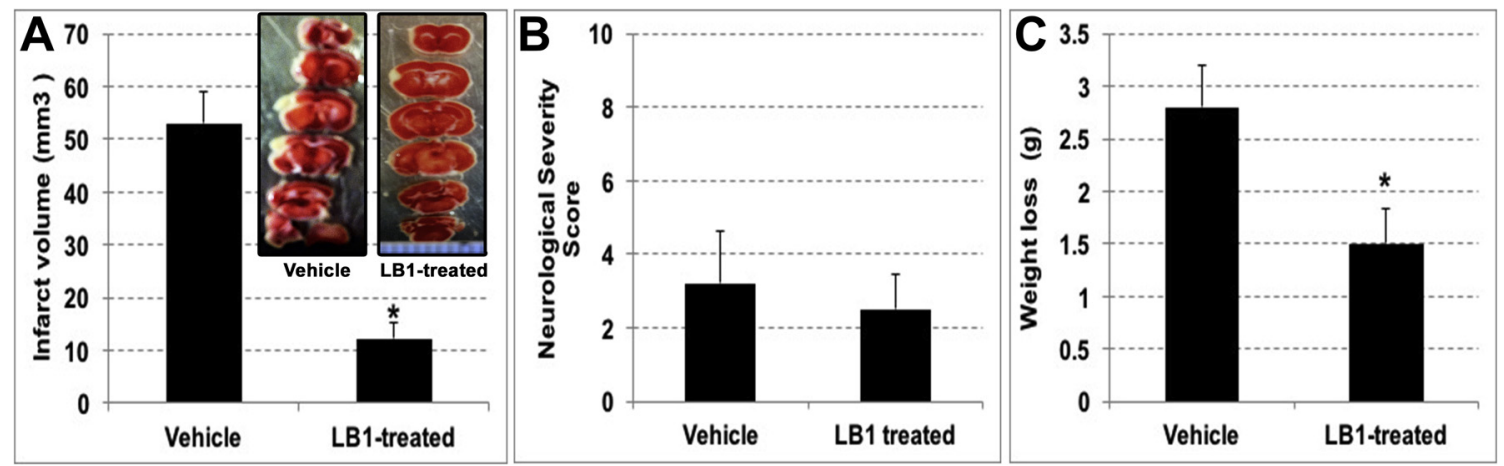

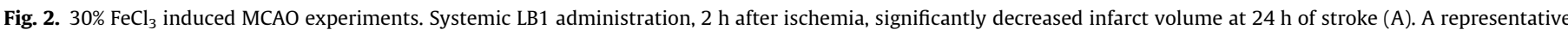

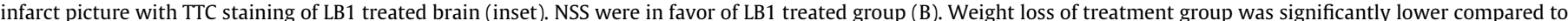
vehicle injected group (C).
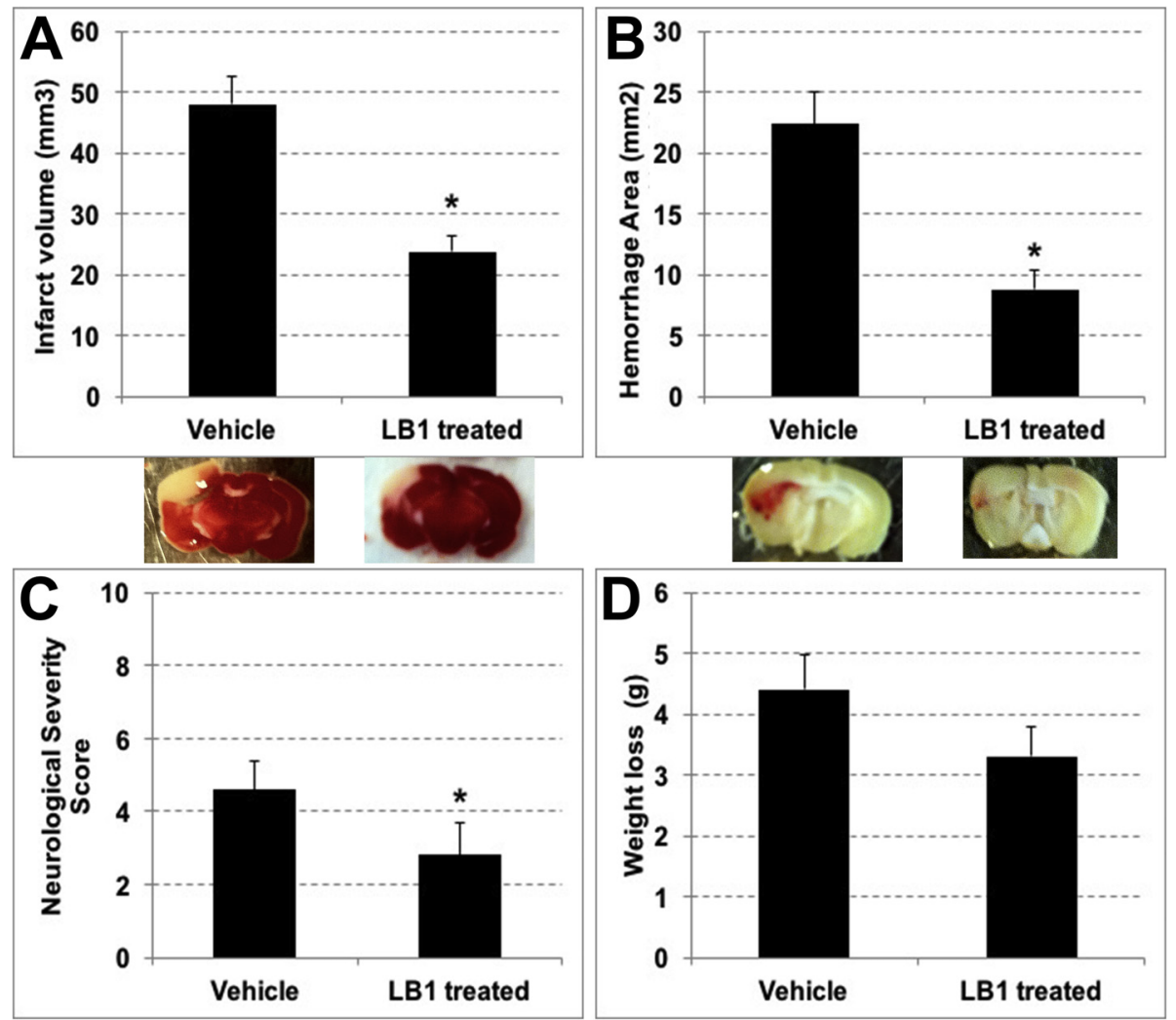

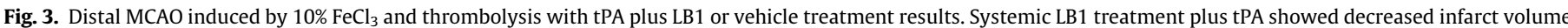

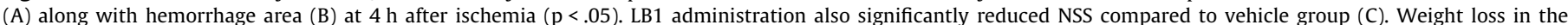
treatment group was lower than in the vehicle group, but the difference was not statistically significant (D).

It is noteworthy to mention the limitations of this study like tPA plus LB1 treatment beyond $4 \mathrm{~h}$ after stroke was not investigated. Especially 6 or $8 \mathrm{~h}$ after stroke could be studied in future projects for translational purposes. Second drawback might be that we performed the experiments in different strains of mice within different stroke models. In permanent MCAO model, C57BL6 mice were used and in transient ischemia/ thrombolysis MCAO groups, $\mathrm{CD} 1$ mice were used. Here our purpose was to show the applicability of $\mathrm{FeCl}_{3}$ _induced MCA thrombosis model in different strains, so that different stroke laboratories would prefer this model in their experiments due to the fact that this model is easy to learn, cheap and it also results in consistent infarct volume (Karatas et al., 2011). In addition, permanent and transient ischemia models would be feasible to use with different concentrations of $\mathrm{FeCl}_{3}$ application.
FeCl3-induced distal MCAO model would be useful to screen novel drugs for acute phase stroke treatments, both with or without thrombolysis. LB1 treatment is proven to have significant alleviating effects on several models of stroke and represents a new promising agent for stroke therapy, either alone or coadministered with tPA.

\section{Experimental procedures}

All animal experiments were performed following protocols approved by the Massachusetts General Hospital Institutional Animal Care and Use Committee in accordance with the National Institutes of Health Guide for the Care and Use of Laboratory Animals. Mice were obtained from Charles River Laboratories. Operators of 
surgeries and the investigators evaluating data were blinded as to treatment groups.

\subsection{Ferric chloride induced focal cerebral ischemia model}

Mice were kept under anesthesia with $1.5 \%$ isoflurane in a nitrous oxide/oxygen mixture via a facemask. The body temperature was monitored by a rectal probe and maintained at $37 \pm 0.2$ ${ }^{\circ} \mathrm{C}$ by a homoeothermic blanket control unit. A ferric chlorideinduced thrombosis model was used to occlude the distal MCA as described in Karatas et al. (Karatas et al., 2011). Briefly, mice were placed in a stereotaxic frame, a scalp incision was made and the right temporal muscle was dissected. The area between zygomatic arch and squamous bone was thinned by a high-speed drill and cooled with saline. MCA trace was visualized and a thin bone film over MCA was lifted up. Then a Laser-Doppler flowmetry probe was placed $2 \mathrm{~mm}$ posterior, $6 \mathrm{~mm}$ lateral to the bregma to monitor the regional cerebral blood flow ( $\mathrm{rCBF}$ ). After obtaining a stable epoch of the pre-ischemic $\mathrm{rCBF}$, a piece of $\mathrm{FeCl}_{3}$ saturated filter paper was placed over the intact dura mater along the trace of MCA and the rCBF was continuously monitored.

\subsection{Experimental groups}

In the permanent ischemia groups, $30 \%$ of $\mathrm{FeCl}_{3}$ was used to occlude distal MCA in C57Bl6 mice. LB1 (50 mg/kg) or vehicle (DMSO) treatments were given intraperitoneally (ip) $2 \mathrm{~h}$ after MCAO. This time point was chosen in accordance with the previous studies of the van Leyen group (Jin et al., 2008; van Leyen et al., 2006; Yigitkanli et al., 2013). These groups are used to investigate the effect of LB1 on infarct volume in the permanent distal MCAO that is one of the major subtypes of the human stroke.

In transient ischemia groups, $10 \% \mathrm{FeCl}_{3}$ was used to initiate distal MCA occlusion in CD1 mice. In order to mimic human acute stroke treatment, $4 \mathrm{~h}$ after onset of ischemia either LB1 $(50 \mathrm{mg} /$ $\mathrm{kg}$ ) or vehicle (DMSO) was injected ip and at the same time, tPA (Activase; Genentech, South San Francisco, CA) $10 \mathrm{mg} / \mathrm{kg}$ (the dosage commonly used in rodents) was administered iv over 20 min for thrombolysis. Outcomes were measured using the parameters of infarct and hemorrhage volumes, neurological severity score, weight loss, and reperfusion rate. $24 \mathrm{~h}$ after the induction of ischemia, animals were sacrificed following transcardial perfusion of saline.

\subsection{Neurological severity score}

Mice were tested and scored for neurological deficits using a Neurological Severity Score (NSS), $24 \mathrm{~h}$ after onset of ischemia. One day before focal ischemic injury, mice were tested to obtain pre-injury baselines. A 10 point neurological score was employed with slight modifications (Chen et al., 1996). The score consists of 10 individual clinical parameters, including tasks on motor function, alertness, and physiological behavior, whereby 1 point is given for failure. A maximal NSS of 10 point indicates severe neurological dysfunction with failure at all tasks.

\subsection{Infarction volumes}

Following transcardial perfusion with PBS to remove blood, mice were sacrificed. Ischemic brain damage was assessed by 2,3,5-triphenyltetrazolium hydrochloride (TTC) staining. For that purpose, brains were quickly removed and placed in ice-cold saline for $5 \mathrm{~min}$, then cut into 2-mm-thick coronal slices. Sections were incubated in saline containing 2\% TTC (Sigma, USA) for $20 \mathrm{~min}$. The infarcted area, outlined in white, was measured using the image $\mathrm{J}$ on the posterior surface of each coronal slice, and infarction volume was calculated by multiplying the sum of the infarct areas of five sequential sections by $2 \mathrm{~mm}$ (section thickness). The infarct was most prominent on sections two and three.

\subsection{Evaluation of hemorrhage area}

After $24 \mathrm{~h}$ of ischemia, mice were sacrificed following transcardial perfusion with saline. Brains were removed and photographed. Tissues were then immersed in 4\% paraformaldehyde overnight. Cryoprotection was obtained with $15 \%$ and $30 \%$ sucrose solutions at $4{ }^{\circ} \mathrm{C}$. Following cryoprotection $20 \mu \mathrm{m}$ thick frozen coronal sections were taken with a cryostat. Sections were hydrated with $\mathrm{PBS}$ for $5 \mathrm{~min}$, after that they were incubated in diaminobenzidine (DAB) staining solution (Vector, USA) for $15 \mathrm{~min}$ and washed with $\mathrm{PBS}$ for $5 \mathrm{~min}$. Hydrogen peroxide oxidizes DAB in the presence of hemoglobin, and it gives a dark-brown color. DAB specifically marks hemorrhage area and non-hemorrhagic areas are not stained (Garcia-Yebenes et al., 2011; Wakisaka et al., 2010). Nissl staining was used to see background. For this purpose, $0.5 \%$ cresyl violet in $0.1 \%$ acetic acid solution was applied for $2 \mathrm{~min}$ and sections were washed with tap water. Then dehydration was obtained by $70 \%, 95 \%$ and $100 \%$ alcohol for $30 \mathrm{~s}$ in each and xylene was used for immersion. The border of each DAB stained area was drawn by using NIH Image $\mathrm{J}$ and hemorrhage area $\left(\mathrm{mm}^{2}\right)$ was calculated by summation of the areas.

\subsection{Immunohistochemistry}

For immunohistochemistry staining to determine LOX immunoreactivity, $30 \% \mathrm{FeCl}_{3}$ was chosen to permanently occlude distal MCA in C57Bl6 mice and sham operated mice were used as controls. In sham operated mice there was no rCBF change after $\mathrm{NaCl}$ soaked filter paper application on MCA. Immunohistochemistry was performed on formalin-fixed sections, according to Pallast et al. (Pallast et al., 2010). Brains were perfused transcardially first with saline, then with $4 \%$ formalin. They were rapidly removed and stored in $4 \%$ formalin overnight. The next day, brains were transferred to a buffer containing $15 \%$ sucrose for $24 \mathrm{~h}$ and followed by an immersion in a 30\% sucrose solution. Samples were sectioned into $20-\mu \mathrm{m}$ coronal sections on a freezing microtome. After staining with primary antibodies and fluorescent-tagged secondary antibodies, sections were analyzed on a Zeiss LSM 5 Pascal scanning confocal microscope. Antibodies used for double staining were a rabbit polyclonal antiserum raised against the C-terminal peptide of 12/15-LOX and affinity purified against the peptide used for immunization, a mouse monoclonal antibody MDA2, which recognizes malondialdehyde-modified lysine residues, and an antibody to apoptosis-inducing factor (AIF) (Palinski et al., 1990).

\subsection{Statistical analysis}

Data are given as mean \pm sem. Group comparisons were performed by means of Mann-Whitney's $U$-test. Probability values $<.05$ were considered significant.

\section{Conflict of interest}

The authors declare that they have no conflict of interest.

\section{Ethical Approval}

All applicable international, national, and institutional guidelines for the care and use of animals were followed. 


\section{Acknowledgement}

Funding through NIH Grants R01NS049430 and R21NS087165 (to K.v.L.) is gratefully acknowledged.

\section{References}

Chen, Y., Constantini, S., Trembovler, V., Weinstock, M., Shohami, E., 1996. An experimental model of closed head injury in mice: pathophysiology, histopathology, and cognitive deficits. J. Neurotrauma 13, 557-568.

Denorme, F., Langhauser, F., Desender, L., Vandenbulcke, A., Rottensteiner, H., Plaimauer, B., Francois, O., Andersson, T., Deckmyn, H., Scheiflinger, F., Kleinschnitz, C., Vanhoorelbeke, K., De Meyer, S.F., 2016. ADAMTS13mediated thrombolysis of t-PA-resistant occlusions in ischemic stroke in mice. Blood 127, 2337-2345.

Fisher, M., Feuerstein, G., Howells, D.W., Hurn, P.D., Kent, T.A., Savitz, S.I., Lo, E.H., Group, S., 2009. Update of the stroke therapy academic industry roundtable preclinical recommendations. Stroke 40, 2244-2250.

Garcia-Yebenes, I., Sobrado, M., Zarruk, J.G., Castellanos, M., Perez de la Ossa, N., Davalos, A., Serena, J., Lizasoain, I., Moro, M.A., 2011. A mouse model of hemorrhagic transformation by delayed tissue plasminogen activator administration after in situ thromboembolic stroke. Stroke 42, 196-203.

Hardingham, G.E., Lipton, S.A., 2011. Regulation of neuronal oxidative and nitrosative stress by endogenous protective pathways and disease processes. Antioxid. Redox Signaling 14, 1421-1424.

Hossmann, K.A., 2012. The two pathophysiologies of focal brain ischemia: implications for translational stroke research. J. Cereb. Blood Flow Metab. 32. 1310-1316.

Jin, G., Arai, K., Murata, Y., Wang, S., Stins, M.F., Lo, E.H., van Leyen, K., 2008. Protecting against cerebrovascular injury: contributions of 12/15-lipoxygenase to edema formation after transient focal ischemia. Stroke 39, 2538-2543.

Karatas, H., Erdener, S.E., Gursoy-Ozdemir, Y., Gurer, G., Soylemezoglu, F., Dunn, A. K., Dalkara, T., 2011. Thrombotic distal middle cerebral artery occlusion produced by topical $\mathrm{FeCl}(3)$ application: a novel model suitable for intravital microscopy and thrombolysis studies. J. Cereb. Blood Flow Metab. 31, 14521460.

Kaur, J., Zhao, Z., Klein, G.M., Lo, E.H., Buchan, A.M., 2004. The neurotoxicity of tissue plasminogen activator? J. Cereb. Blood Flow Metab. 24, 945-963.

Khanna, S., Roy, S., Slivka, A., Craft, T.K., Chaki, S., Rink, C., Notestine, M.A., DeVries, A.C., Parinandi, N.L., Sen, C.K., 2005. Neuroprotective properties of the natural vitamin E alpha-tocotrienol. Stroke 36, 2258-2264.

Lackland, D.T., Roccella, E.J., Deutsch, A.F., Fornage, M., George, M.G., Howard, G. Kissela, B.M., Kittner, S.J., Lichtman, J.H., Lisabeth, L.D., Schwamm, L.H., Smith, E. E., Towfighi, A., American Heart Association Stroke Council, Council on Cardiovascular and stroke Nursing Council on Quality of Care and Outcomes Research, Council on Functional Genomics and Translational Biology, 2014. Factors influencing the decline in stroke mortality: a statement from the American Heart Association/American Stroke Association. Stroke 45, 315-353.

Lees, K.R., Bluhmki, E., von Kummer, R., Brott, T.G., Toni, D., Grotta, J.C., Albers, G.W., Kaste, M., Marler, J.R., Hamilton, S.A., Tilley, B.C., Davis, S.M., Donnan, G.A., Hacke, W., Ecass, A.N., Group, E.r.-P.S., Allen, K., Mau, J., Meier, D., del Zoppo, G., De Silva, D.A., Butcher, K.S., Parsons, M.W., Barber, P.A., Levi, C., Bladin, C. Byrnes, G., 2010. Time to treatment with intravenous alteplase and outcome in stroke: an updated pooled analysis of ECASS, ATLANTIS, NINDS, and EPITHET trials. Lancet 375, 1695-1703.

Liu, Y., Zheng, Y., Karatas, H., Wang, X., Foerch, C., Lo, E.H., van Leyen, K., 2017. 12/ 15-Lipoxygenase inhibition or knockout reduces warfarin-associated hemorrhagic transformation after experimental stroke. Stroke 48, 445-451.
Lo, E.H., Dalkara, T., Moskowitz, M.A., 2003. Mechanisms, challenges and opportunities in stroke. Nat. Rev. Neurosci. 4, 399-415.

Lo, E.H., Moskowitz, M.A., Jacobs, T.P., 2005. Exciting, radical, suicidal: how brain cells die after stroke. Stroke 36, 189-192.

Moskowitz, M.A., Lo, E.H., Iadecola, C., 2010. The science of stroke: mechanisms in search of treatments. Neuron 67, 181-198.

National Institute of Neurological Disorders and stroke rt-PA Stroke Study Group, 1995. Tissue plasminogen activator for acute ischemic stroke. N. Engl. J. Med. 333, 1581-1587.

Niizuma, K., Endo, H., Chan, P.H., 2009. Oxidative stress and mitochondrial dysfunction as determinants of ischemic neuronal death and survival. J. Neurochem. 109 (Suppl 1), 133-138.

Palinski, W., Yla-Herttuala, S., Rosenfeld, M.E., Butler, S.W., Socher, S.A. Parthasarathy, S., Curtiss, L.K., Witztum, J.L., 1990. Antisera and monoclona antibodies specific for epitopes generated during oxidative modification of low density lipoprotein. Arteriosclerosis 10, 325-335.

Pallast, S., Arai, K., Pekcec, A., Yigitkanli, K., Yu, Z., Wang, X., Lo, E.H., van Leyen, K. 2010. Increased nuclear apoptosis-inducing factor after transient focal ischemia: a 12/15-lipoxygenase-dependent organelle damage pathway. J. Cereb. Blood Flow. Metab. 30, 1157-1167.

Park, H.A., Kubicki, N., Gnyawali, S., Chan, Y.C., Roy, S., Khanna, S., Sen, C.K., 2011 Natural vitamin E alpha-tocotrienol protects against ischemic stroke by induction of multidrug resistance-associated protein 1. Stroke 42, 2308-2314.

van Leyen, K., Duvoisin, R.M., Engelhardt, H., Wiedmann, M., 1998. A function for lipoxygenase in programmed organelle degradation. Nature 395, 392-395.

van Leyen, K., Kim, H.Y., Lee, S.R., Jin, G., Arai, K., Lo, E.H., 2006. Baicalein and 12/15lipoxygenase in the ischemic brain. Stroke 37, 3014-3018.

van Leyen, K., Holman, T.R., Maloney, D.J., 2014. The potential of 12/15 lipoxygenase inhibitors in stroke therapy. Future Med. Chem. 6, 1853-1855.

Wakisaka, Y., Chu, Y., Miller, J.D., Rosenberg, G.A., Heistad, D.D., 2010. Spontaneous intracerebral hemorrhage during acute and chronic hypertension in mice. J Cereb. Blood Flow. Metab. 30, 56-69.

Wang, X., Tsuji, K., Lee, S.R., Ning, M., Furie, K.L., Buchan, A.M., Lo, E.H., 2004. Mechanisms of hemorrhagic transformation after tissue plasminogen activator reperfusion therapy for ischemic stroke. Stroke 35, 2726-2730.

Writing Group Members, Mozaffarian, D., Benjamin, E.J., Go, A.S., Arnett, D.K., Blaha, M.J., Cushman, M., Das, S.R., de Ferranti, S., Despres, J.P., Fullerton, H.J., Howard, V.J., Huffman, M.D., Isasi, C.R., Jimenez, M.C., Judd, S.E., Kissela, B.M., Lichtman, J. H., Lisabeth, L.D., Liu, S., Mackey, R.H., Magid, D.J., McGuire, D.K., Mohler 3rd, E. R., Moy, C.S., Muntner, P., Mussolino, M.E., Nasir, K., Neumar, R.W., Nichol, G., Palaniappan, L., Pandey, D.K., Reeves, M.J., Rodriguez, C.J., Rosamond, W., Sorlie, P.D., Stein, J., Towfighi, A., Turan, T.N., Virani, S.S., Woo, D., Yeh, R.W., Turner, M B., American Heart Association Statistics Committee, Stroke Statistics Subcommittee, 2016. Heart disease and stroke statistics-2016 update: a report from the American Heart Association. Circulation 133. e38-360.

Yepes, M., Roussel, B.D., Ali, C., Vivien, D., 2009. Tissue-type plasminogen activator in the ischemic brain: more than a thrombolytic. Trends Neurosci. 32, 48-55.

Yigitkanli, K., Pekcec, A., Karatas, H., Pallast, S., Mandeville, E., Joshi, N., Smirnova, N. Gazaryan, I., Ratan, R.R., Witztum, J.L., Montaner, J., Holman, T.R., Lo, E.H., van Leyen, K., 2013. Inhibition of 12/15-lipoxygenase as therapeutic strategy to treat stroke. Ann. Neurol. 73, 129-135.

Yigitkanli, K., Zheng, Y., Pekcec, A., Lo, E.H., van Leyen, K., 2017. Increased 12/15 lipoxygenase leads to widespread brain injury following global cerebra ischemia. Transl. Stroke. Res. 8, 194-202.

Zhao, H., Yenari, M.A., Cheng, D., Barreto-Chang, O.L., Sapolsky, R.M., Steinberg, G.K. 2004. Bcl-2 transfection via herpes simplex virus blocks apoptosis-inducing factor translocation after focal ischemia in the rat. J. Cereb. Blood Flow. Metab. 24, 681-692. 